\begin{tabular}{|c|c|c|}
\hline 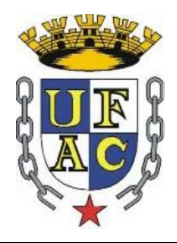 & $\begin{array}{c}\text { UÁQUIRI } \\
\text { Revista do Programa de Pós-Graduação em Geografia } \\
\text { UÁQUIRI - PPGGEO, v. } 2 \text { n. 1, p. } 26 \text { - 44, ano } 2020 \\
\text { Home page: } \underline{\text { https://periodicos.ufac.br/index.php/Uaquiri }}\end{array}$ & PPG \\
\hline & & ISSN 2675-4088 \\
\hline
\end{tabular}

\title{
CARACTERIZAÇÃO FISIOGRÁFICA DO MUNICÍPIO DE BUJARI - AC: SUBSÍDIO AO ZONEAMENTO GEOAMBIENTAL
}

\author{
Ezaque Saraiva do Nascimento ${ }^{1 *}$, Waldemir Lima dos Santos ${ }^{2}$ \\ ORCID: https://orcid.org/0000-0003-0604-0137; https://orcid.org/0000-0002-5306-5612
}

${ }^{1}$ Graduado em Geografia (Bacharelado), pela Universidade Federal do Acre, Centro de Filosofia e Ciências Humanas, Rio Branco, Acre, Brasil; ${ }^{2}$ Doutor, professor do Programa de Pós-graduação em Geografia da Universidade Federal do Acre, Centro de Filosofia e Ciências Humanas, Rio Branco, Acre, Brasil.

* ezaquesn@gmail.com

Recebido em: 18/02/2020. Aceito em: 10/04/2020. Publicado em: 22/06/2020 DOI:

\begin{abstract}
Proporcionar o planejamento urbano em pequenas cidades sobretudo quando falamos da Região Norte do Brasil, não tem sido uma tarefa simples. Considerando o fator histórico de ocupação das terras acreanas em que teve os rios como principal via de acesso e a borracha como principal economia da região, fez emergir os primeiros povoados que posteriormente se transformariam em pequenas cidades que ao longo dos anos cresceram e continuam crescendo de forma desordenada e sem planejamento. Para o ordenamento de um determinado espaço, ou seja, promover o mínimo de planejamento técnico com a manutenção do meio ambiente, utilização de recursos de forma planejada, indicação para uso especifico e ao mesmo tempo com a promoção do desenvolvimento local, se faz necessário o conhecimento mínimo dos elementos geoambientais presentes nesse espaço sujeito a transformações. Para tanto, este trabalho teve como objetivo principal realizar uma caracterização fisiográfica detalhada dos elementos físicos presentes no território do município de Bujari, como instrumento de análise e embasamento para o desenvolvimento de um futuro zoneamento geoambiental para o município. Os principais elementos físicos caracterizados tendo como recorte o perímetro municipal foram: a Geologia, Geomorfologia, Solos, Hidrografia e Uso do Solo. Todas as análises espaciais bem como o mapeamento realizado em nosso estudo, foi desenvolvido em ambiente SIG (Sistema de Informação Geográfica).
\end{abstract}

RESUMO

Palavras-chave: caracterização geoambiental; elementos geoambientais; planejamento territorial.

\section{PHYSIOGRAPHIC CHARACTERIZATION OF THE CITY OF BUJARI - AC: SUBSIDY FOR GEO-ENVIRONMENTAL ZONING}

\begin{abstract}
Providing urban planning in small towns, especially when it comes to Northern Brazil, has not been a simple task. Considering the historical factor of occupation of the Acrean lands in which rivers were the main access road and rubber as the main economy of the region, it gave rise to the first settlements that would later become small towns that over the years have grown and continue to grow. disorderly and unplanned manner. For the planning of a certain space, that is, to promote the minimum of technical planning with the maintenance of the environment, use of resources in a planned way, indication for specific use and at the same time with the promotion of local development, it is necessary to minimum
\end{abstract}


knowledge of the geoenvironmental elements present in this space subject to transformations. Therefore, this work had as main objective to perform a detailed physiographic characterization of the physical elements present in the territory of the municipality of Bujari, as an instrument of analysis and basis for the development of a future geoambietal zoning for the municipality. The main physical elements characterized based on the municipal perimeter were: Geology, Geomorphology, Soils, Hydrography and Land Use. All spatial analysis as well as the mapping performed in our study was developed in GIS (Geographic Information System) environment.

Keywords: geoenvironmental characterization, geoenvironmental elements territorial planning.

\title{
CARACTERIZACIÓN FISIOGRÁFICA DE LA CIUDAD DE BUJARI - AC: SUBVENCIÓN PARA LA ZONIFICACIÓN GEOAMBIENTAL
}

\begin{abstract}
RESUMEN
Proporcionar planificación urbana en ciudades pequeñas, especialmente cuando se trata de la Región Norte de Brasil, no ha sido una tarea sencilla. Teniendo en cuenta el factor histórico de ocupación de las tierras de Acre en las que los ríos fueron la principal ruta de acceso y el caucho como la principal economía de la región, surgieron los primeros asentamientos que luego se convertirían en pequeñas ciudades que a lo largo de los años han crecido y continúan creciendo. desordenada y no planificada. Para ordenar un espacio dado, es decir, para promover el mínimo de planificación técnica con el mantenimiento del medio ambiente, el uso de los recursos de manera planificada, la indicación para un uso específico y al mismo tiempo con la promoción del desarrollo local, es necesario conocimiento mínimo de los elementos geoambientales presentes en este espacio sujeto a cambios. Para ello, este trabajo tuvo como objetivo principal llevar a cabo una caracterización fisiográfica detallada de los elementos físicos presentes en el territorio del municipio de Bujari, como instrumento de análisis y fundamento para el desarrollo de una futura zonificación geoambietal para el municipio. Los principales elementos físicos caracterizados por tener el perímetro municipal cortado fueron: geología, geomorfología, suelos, hidrografía y uso del suelo. Todos los análisis espaciales, así como el mapeo realizado en nuestro estudio, se desarrollaron en un entorno SIG (Sistema de Información Geográfica)
\end{abstract}

Palabras clave: caracterización geoambiental, elementos geoambientales planificación territorial.

\section{INTRODUÇÃ̃O}

O processo histórico de ocupação territorial da Amazônia associado ao modelo de desenvolvimento econômico-social ocorrido na região, tem proporcionado aos territórios municipais, um modelo de ocupação desordenado, irregular com ausência de planejamento urbano e implementação de políticas públicas desconectas, que afetam a grande maioria dos municípios que compõem essa região do país.

Nessa perspectiva propor políticas de planejamento territorial para as cidades da região amazônica na atualidade, requer um exercício contínuo de inserção do componente "ambiental" uma vez que as políticas públicas e discussões sobre desenvolvimento regional ou mesmo local, estão quase sempre abordando à questão do "desenvolvimento sustentável." 
Dentro da perspectiva de planejamento ambiental, o ordenamento territorial, pode ser entendido como uma alternativa viável para promoção de uma gestão mais eficiente dos espaços. Pode ser utilizado como alternativa de prevenção contra possíveis impactos ambientais, uma vez que permite o reconhecimento mais detalhado por meio dos diferentes tipos de zoneamentos por ele exigido.

Nesse contexto, o conhecimento numa maior escala das diferentes unidades geoambientais do território do município de Bujari será de grande relevância, uma vez que os resultados servirão de embasamento nas discussões sobre as políticas de melhoria estrutural, sobretudo no âmbito do planejamento ambiental territorial do município.

O uso das geotecnologias principalmente o Sistema de Informação Geográfica (SIG) e utilização de técnicas de sensoriamento remoto, mostraram-se ferramentas relevantes na construção de nossa pesquisa. Com auxílio desses equipamentos foi possível a realização da caracterização permitindo a compartimentação e posterior análise desses espaços.

A ausência de informações espaciais sobre o município é um fator evidente sendo este um dos motivos que nos despertou o interesse no desenvolvimento desta pesquisa. Nessa cidade, não há informações georreferenciadas sobre as características físicas, levantamentos de potencialidades ambientais, de áreas verdes, áreas de preservação permanente, rede hidrográfica etc. As poucas informações existentes, restringe-se somente a mapas de loteamentos sem referência espacial.

Com o atual "modelo político" adotado pela prefeitura do município (rodízio de cargos comissionados que entram e saem de acordo com a gestão partidária), os setores responsáveis pelo meio ambiente, agricultura, cadastro imobiliário por exemplo, (por serem normalmente cargos políticos) não conseguem exercer um trabalho consistente, adotando um planejamento a médio e longo prazo resume-se a trabalhos cotidianos sem muitas perspectivas de inovações.

De acordo com o Estatuto das Cidades o município não é obrigado a elaborar seu Plano Diretor, pois, o número de habitantes é inferior ao exigido pela Lei para a implementação desse instrumento. No entanto, defendemos a ideia de que há a necessidade eminente de planejamento do território independente do município atingir seus 20.000 habitantes conforme orienta a Legislação, uma vez que os problemas ambientais iniciam desde muito cedo, quando surgem as primeiras aglomerações urbanas.

Por estes percalços identificados, é que apontamos nossa proposta de pesquisa como contribuição ao projeto de planejamento territorial, com o objetivo de realizar a caraterização das principais unidades geoambientais presentes no território municipal, tais como: geologia, 
geomorfologia, pedologia, vegetação, hidrografia e uso do solo, com vistas a subsidiar o desenvolvimento de um futuro zoneamento geoambiental.

\section{FUNDAMENTAÇÃO TEÓRICA}

\subsection{O Território}

O termo território é bastante comum e muito utilizado na geografia em pesquisas que envolvam a componente "espacialidade" em seu contexto de abrangência. Souza (2010) na tentativa de explicação sobre o termo, nos apresenta um conceito formulado sobre o território definido como "chão da população, isto é, sua identidade, o fato e o sentimento de pertencer àquilo que nos pertence. $\mathrm{O}$ território é a base do trabalho, da residência, das trocas materiais e espirituais e da vida, sobre os quais influi" (SANTOS, 2000, apud SOUZA, 2010, p. 1).

De acordo com essa conceituação o território pode ser entendido como sendo o "espaço" de inserção da sociedade onde se mantém as relações sociais, ou seja, onde a sociedade vive, trabalha, se reproduz socialmente, tornando esse espaço útil a sociedade.

Complementar a essa afirmação, Santos (2003 apud Souza 2010, p. 1) apresenta o território como "uma extensão territorial apropriada e usada e não somente como um espaço geográfico." O território nesse sentido é resultado das relações sociais e portanto, representa sua importância enquanto espaço útil para a sociedade.

\subsection{Ordenamento Territorial}

A partir dessa breve contextualização inicial sobre território abordaremos a seguir, a proposta de ordenamento territorial enquanto ferramenta de planejamento, através de uma síntese geral com base em alguns trabalhos já realizados sobre a temática do ordenamento.

Para Souza (2010, p. 3), o termo Ordenamento Territorial, tal qual como conhecemos hoje, "surgiu pela primeira vez no continente europeu, mas não de forma igualitária em toda a sua extensão, ele evoluiu em termos e tempos diferentes nos diversos países."

Ainda de acordo com esse autor, a Carta Europeia de Ordenação do Território tem sido um dos principais documentos históricos oficiais com aceitação, quando se trata do tema abordado, e ela diz que: 
O Ordenamento Territorial é a tradução espacial das políticas econômica, social, cultural e ecológica da sociedade. [...] O ordenamento do território deve ter em consideração a existência de múltiplos poderes de decisão, individuais e institucionais que influenciam a organização do espaço, o caráter aleatório de todo o estudo prospectivo, os constrangimentos do mercado, as particularidades dos sistemas administrativos, a diversidade das condições sócio-econômicas e ambientais. Deve, no entanto, procurar conciliar estes fatores da forma mais harmoniosa possível. (CONSELHO DA EUROPA, 1988, apud SOUZA, 2010, p. 2).

Na visão de Rückert (2004 apud SOUZA 2010, p. 3) na América do Sul, o ordenamento territorial surgiu sob as bases econômicas do modelo central-desenvolvimentista sob a competência da administração central que praticava um planejamento centralizado.

No Brasil, o ordenamento territorial é constitucional. Nas bibliografias consultadas, a inserção do ordenamento territorial na Constituição Federal de 1988, marca o início das discussões sobre a temática do ordenamento territorial nas pautas de planejamento nacional. De acordo com (BRASIL, 1988, p. 26), "Compete à União: IX - elaborar e executar planos nacionais e regionais de ordenação do território e de desenvolvimento econômico e social;" no referido documento, (BRASIL, 1988, p. 34), indica que "Compete aos Municípios: VIII promover, no que couber, adequado ordenamento territorial, mediante planejamento e controle do uso do solo, do parcelamento e da ocupação do solo urbano;"

No entanto, para Souza (2010, p. 4), apesar de constitucional, as discussões sobre a temática do ordenamento territorial só virá a apresentar status de política, quinze anos mais tarde (em 2003), quando realmente vem se tornar uma Política Nacional de Ordenamento Territorial - PNOT, tornando-se um instrumento de gestão integrador das políticas municipais com às nacionais.

O ordenamento territorial é um campo de estudo inserido dentro do contexto maior de planejamento ambiental, por sua vez, o planejamento ambiental pode ser entendido como instrumento norteador das políticas ambientais de gestão territorial no sentido de organizar o espaço para assim melhorar o aproveitamento do potencial existente, respeitando as especificidades e restrições desses territórios submetidos à política ambiental.

Nessa perspectiva a proposta de caracterização territorial do município de Bujari, configurou-se como contribuição ao zoneamento geoambiental, este por sua vez se realizado, contribuirá para a elaboração do Plano Diretor Municipal que por meio de seus mecanismos legais, poderá esboçar as estratégias necessárias para o alcance da organização dos espaços físicos do município. 


\subsection{Zoneamento geoambiental}

$\mathrm{Na}$ perspectiva de zoneamento enquanto ferramenta de planejamento de ambientes, Batistela (2007, p. 49) diz que o zoneamento é considerado, em uma análise geral, como um instrumento de planejamento urbano (por excelência) e teve suas primeiras propostas disseminadas na Europa. Nos Estados Unidos o planejamento destacou-se historicamente, sendo o "carro-chefe" do movimento de planejamento desse país.

Fica evidente, portanto, que o estudo das paisagens ambientais utilizando como ferramenta o zoneamento, podem ser utilizados dentro de uma perspectiva de planejamento territorial ambiental. Muito embora sabemos que análises de paisagens não devem ser realizadas de forma isolada, no entanto, o que propomos é a compreensão das partes separadas para assim compreendermos o todo.

A respeito do zoneamento geoambiental, Santos (2004) apud Oliveira (2012, p. 22) relata que esta modalidade "consiste na compartimentação, com base nas características homogêneas, das unidades geoambientais que são obtidas a partir da integração dos dados do meio natural."

Para Cabral (2014), a análise geoambiental de uma determinada área de estudo, é uma ferramenta essencial para o planejamento de ações implementadas com objetivos específicos de utilização de recursos naturais de forma sustentável, pois, permite o reconhecimento da área. Esse reconhecimento é possível por meio da localização, identificação e quantificação desses recursos. (CABRAL, 2014, p. 36).

Para Oliveira (2012, p. 22), o zoneamento geoambiental se constitui em um diagnóstico do meio físico-natural, a partir do estudo integrado da geologia, relevo, hidrografia, cobertura vegetal, solo, clima e uso do solo, orientado para subsidiar o planejamento e ordenamento ambiental territorial.

A partir destas constatações, a realização de "análise geoambiental de uma determinada área de estudo se torna uma ferramenta essencial para o planejamento de ações a serem executadas com vistas a utilização dos recursos naturais ali presentes de forma sustentável [...]" (CABRAL, 2014 p. 36). 


\subsection{Método Sistêmico de Análise}

O método científico é um instrumento indispensável para quem se propõe a desenvolver pesquisas científicas. Independente do ramo a que se destine, a utilização de métodos implica em seguir um direcionamento para o alcance dos objetivos almejados.

Por sua importância, a adoção de métodos no campo da pesquisa científica não pode deixar de estar presente nos mais diversos estudos, sobretudo nos que envolvam pesquisas científicas. O tipo de método aplicado dependerá obviamente do objeto de pesquisa a ser investigado, um método bem definido certamente contribuirá a responder todas as indagações que possam surgir durante a realização da pesquisa.

Pelo fato de nosso objeto de estudo está relacionado ao campo do meio ambiente, mais precisamente na caracterização de unidades geoambientais, o método aplicado no estudo, está relacionado a Teoria Geral dos Sistemas - TGS, tendo como principal idealizador dessa vertente metodológica no ocidente o biólogo austríaco Ludwig Von Bertalanffy.

Este método como próprio nome diz baseia-se nos princípios dos "sistemas," tema amplo e que encontramos na literatura várias definições sobre o termo, para nosso estudo ficaremos com a definição de Miller (1965) apud Neves (2015, p. 44), em que trata o sistema como sendo um "conjunto de unidades com relação entre si, onde essas unidades possuem propriedades comuns."

Para Bertalanffy (1973) a análise dos estudos realizada por essa perspectiva sistêmica deverá seguir a seguinte orientação:

\footnotetext{
É necessário estudar não somente partes e processos isoladamente, mas também resolver os decisivos problemas encontrados na organização e na ordem que os unifica, resultante da interação dinâmica das partes, tornando o comportamento das partes diferentes quando estudado isoladamente e quando tratado no todo" (BERTALANFFY, 1973; p. 53 apud MARQUES NETO, 2008, p. 70).
}

A Teoria Geral dos Sistemas surge como um método interdisciplinar não sendo exclusividade de uma única ciência, por sua abordagem sistêmica permite a compreensão do "todo" analisado por meio de análises das partes isoladas, estando estas integradas como um verdadeiro sistema. Visto por essa ótica pode ser aplicada por outras disciplinas, sendo uma destas a geografia.

Partindo dessa análise a TGS pode ser utilizada com grande proveito na ciência da geografia, podendo ser utilizada para a investigação das mais diversas linhas de pesquisa, 
sobretudo no campo da geografia física. Sobre essa afirmação respaldamo-nos nos estudos de (LIMBERGER, 2006) que afirma:

\begin{abstract}
Considerando-se o âmbito da Geografia em particular, a abordagem sistêmica favoreceu e dinamizou o desenvolvimento da chamada "Nova Geografia". Serviu, nesta ciência, para uma melhor focalização das suas pesquisas e para delinear com maior exatidão o seu setor de estudo, permitindo também reconsiderações de seus conceitos e uma revitalização de vários setores, com destaque para a Geomorfologia. Foi introduzida por Strahler, em 1950, onde o autor trabalhou com sistemas de drenagem, considerando-o como um sistema aberto. Após Strahler figuram também Culling (1957), Hack (1960), Chorley (1962), Howard (1965), Chorley e Kennedy (1971), trabalhos estes voltados para a área de Geomorfologia, sendo que o último, figura como a contribuição de maior interesse para a Geografia Física (CHRIOSTOFOLETTI, 1979 apud LIMBERGER, 2006, p. 100-101). (Grifo nosso).
\end{abstract}

Pelo exposto, TGS enquanto método científico de abordagem poderá contribuir significativamente com o desenvolvimento de nossa pesquisa, uma vez que nos instiga a fazer análises a luz da perspectiva sistêmica do ambiente, como assim deve ser feito, a fim de ajudar a responder à possíveis indagações recorrentes em estudo de paisagens ambientais.

\title{
3. METODOLOGIA
}

\section{1. Área de Estudo}

O município do Bujari está localizado entre as coordenadas 9³9'49,94418'’ de Latitude Sul e 6757'09,10493'" de Longitude Oeste, em termos administrativos está localizado na mesorregião do Acre e microrregião de Rio Branco, com área territorial de 3.034,86 Km² e população de 8.471 habitantes de acordo com o último censo realizado 2010. (IBGE, 2019).

O processo de formação histórico do município de Bujari ocorreu diretamente com a construção da BR 364, mais precisamente do trecho entre Rio Branco e Sena Madureira. O local onde hoje situa-se a cidade era uma antiga colocação de seringa chamada Bujari, nome que posteriormente seria dado ao município. A colocação pertencia ao antigo Seringal Empresa fundado pelo cearense Neutel Maia em 28 de dezembro de 1882. (TORRES, 1996 p. 8). 
Figura 01: Mapa de localização da área de estudo.

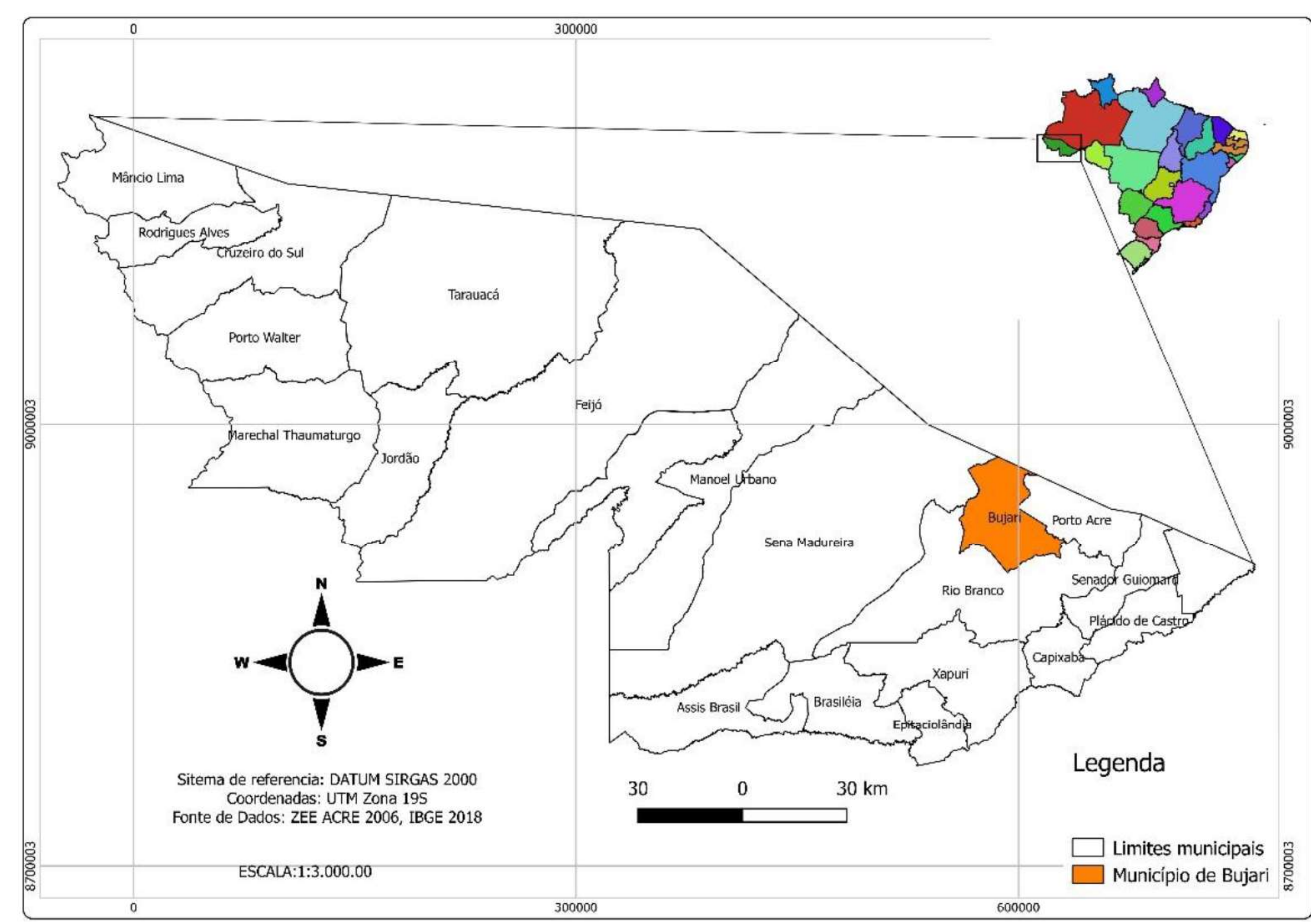

Fonte: Autor, 2019.

\subsection{Etapas da pesquisa}

O primeiro passo para iniciação desse trabalho foi o levantamento bibliográfico e posterior leitura. As principais fontes de pesquisa utilizadas foram dissertações de mestrado e teses de doutorado, além de livros e artigos eletrônicos.

Posteriormente foi realizado o levantamento e organização dos diferentes dados geográficos do município, para posterior processamento e extração de informações relevantes da área de estudo. Vale ressaltar da dificuldade de obtenção dessas informações uma vez tratarse de um município com pouquíssimos trabalhos realizados em termos de mapeamento principalmente na escala proposta por nossa pesquisa. Esses dados foram:

$\checkmark$ Mapas do município;

$\checkmark$ Arquivos em formato shapefile;

$\checkmark$ Imagens de satélite Landsat 8 multiespectral 30m de resolução espacial na escala de $1: 150.000$.

$\checkmark \quad$ Imagens SRTM (Shuttle Radar Topography Mission) de 30m de resolução espacial na escala de 1:150.000. 
Todo o trabalho foi realizado com utilização de software de geoprocessamento livre, nesse caso o software utilizado foi o QGis 2.14.8 Essen versão já estável do programa, além de seus complementos auxiliares para a execução de processamento de imagens.

De posse de todos os dados geográficos, foi necessário inicialmente realizar a padronização no Sistema de Referência já associado a esses dados, foi utilizado o Sistema de Referência DATUM SIRGAS 2000 por se tratar do Datum oficial para o Brasil e para facilitar a análise por meio da sobreposição destes.

Além da utilização dos softwares de geoprocessamento também foi utilizado a planilha eletrônica do Excel versão 2016 para execução de cálculos.

\section{RESULTADOS E DISCUSSÃO}

\subsection{Geologia}

A estrutura geológica consiste na gênese estrutural, ou seja, a constituição inicial da crosta terrestre. Esses arcabouços são formados por meio de processos tectônicos que culminam na concepção do embasamento rochoso sobre o qual está localizada determinada superfície.

De acordo com Cavalcante (2006 p. 9), "no Acre, a unidade geotectônica mais importante é a bacia do Acre que compreende unidades essencialmente cenozoicas, entretanto, em sua porção mais a oeste ocorrem remanescentes mesozoicos e até pré-cambriano."

Para o IBGE (2005), as principais estruturas geológicas do Acre são: a) Complexo Jamari, b) Formação Formosa, c) Serenito República, d) Formação Serra do Divisor, e) Formação Rio Azul, f) Formação Moa, g) Formação Ramon, h) Formação Solimões, i) Formação Cruzeiro do Sul, j) Cobertura Detríto-Laterítica Pleistocênica, k) Terraços Pleistocênicos, 1) Terraços Holocênicos e m) Aluviões Holocênicos.

Vale ressaltar que cada uma das estruturas geológicas ocorreu em Épocas Períodos ou mesmo em Eras diferentes durante o lento processo de formação geológico estrutural do território hoje ocupado pelo Estado do Acre.

De acordo com os dados geoespaciais obtidos do IBGE e utilizados na pesquisa, mais precisamente arquivos em formato shapefile das principais unidades geológicas do território acreano, o município de Bujari encontra-se consolidado sobre as seguintes estruturas geológicas: Formação Solimões, Aluviões Holocênicos e Terraços Pleistocênicos. 
De acordo com o estudo, o território municipal não apresenta muitas variações nas estruturas geológicas o que não o difere das características geológicas do restante do território acreano. Constata-se a existência de $93 \%$ do território municipal consolidado sobre a Formação Solimões, sendo está a estrutura geológica de maior abrangência também em todo o Território Estadual.

$\mathrm{Na}$ tabela abaixo apresentamos alguns dados quantitativos realizados por meio do processamento digital para quantificar os totais de área ocupada por estas formações.

Tabela 1: Totais das áreas Consolidadas das Formações Geológicas do Município de Bujari.

\begin{tabular}{l|cc}
\hline \multicolumn{1}{c|}{ Formação Geológica } & Área Total $\left.\mathbf{( k m}^{2}\right)$ & Percentual (\%) \\
\hline Formação Solimões & $2.822,429$ & 93,0 \\
Aluviões Holocênicos & 127,709 & 4,2 \\
Terraços Pleistocênicos & 82,787 & 2,8 \\
\hline
\end{tabular}

Fonte: Organizado pelo autor -2019 .

De acordo com o IBGE a Formação Aluviões Holocênicos foi desenvolvida a cerca de 10.000 anos, portanto, a mais recente das Formações caracteriza-se por depósitos grosseiros a conglomeráticos, representando residuais de canal; arenosos relativos à barra em pontal e pelíticos representando aqueles de transbordamento. (IBGE, 2019).

A Formação Terraços Pleitocenicos é a de menor proporção no município, foi formada a cerca 1.75 milhões de anos e é caracterizada por depósitos de terraços fluviais antigos e rampas-terraços, constituídos por argilas, siltes e areias, às vezes maciços, de cores avermelhadas. Localmente mostram intercalações lenticulares de argilitos e conglomerados. (IBGE 2019).

E por último a Formação Solimões de maior abrangência no território municipal foi formada a cerca de 5.3 milhões de anos é caracterizada por rochas sedimentares dominantemente pelíticas, altamente fossilíferas, sob a forma de argilitos com intercalações de siltitos, arenitos finos, calcários e material carbonoso (linhito), micáceos. Ambiente redutor predominantemente lacustre, localmente fluvial e flúvio-marinho, com estratificações paralelas e cruzadas tabulares e acanaladas. (IBGE 2019). 


\subsection{Geomorfologia}

A forma em que se apresenta a superfície terrestre deve sempre ser levada em consideração quando falamos de processos de planejamento urbano. A ocupação humana em locais inadequados como encostas ou topos de morro podem acarretar sérios problemas para os gestores municipais que precisam planejar o crescimento os espaços urbanos considerando o fator geomorfológico.

Para Christofoletti (1980), "a geomorfologia é a ciência que estuda as formas do relevo." Nesse sentido o relevo do município de Bujari de acordo com a afirmação de Torres (1996), é caracterizado como de planície, pois, a extensão do município é formada por uma larga faixa de terras planas moderadamente onduladas com existência de terras firmes e de várzeas.

De acordo com os dados altimétricos do Modelo Digital de Elevação - MDE utilizado no estudo, as altitudes do território municipal variam entre 137 a 260 metros de altitude, não havendo, portanto, grandes destaques de elevação ou depressão na área de estudo.

Os dois principais destaques são as duas depressões dos dois maiores mananciais que cortam o município o Igarapé Riozinho e o Rio Antimary. Na parte mais a oeste do município nas divisas com os municípios de Sena Madureira e Rio Branco encontra-se os pontos mais elevados de todo o território municipal passando de cerca de 260 metros de altitude conforme podemos constar nas imagens abaixo.

Figura 02: (a) Hipsometria e (b) Totais das classes altimétricas.

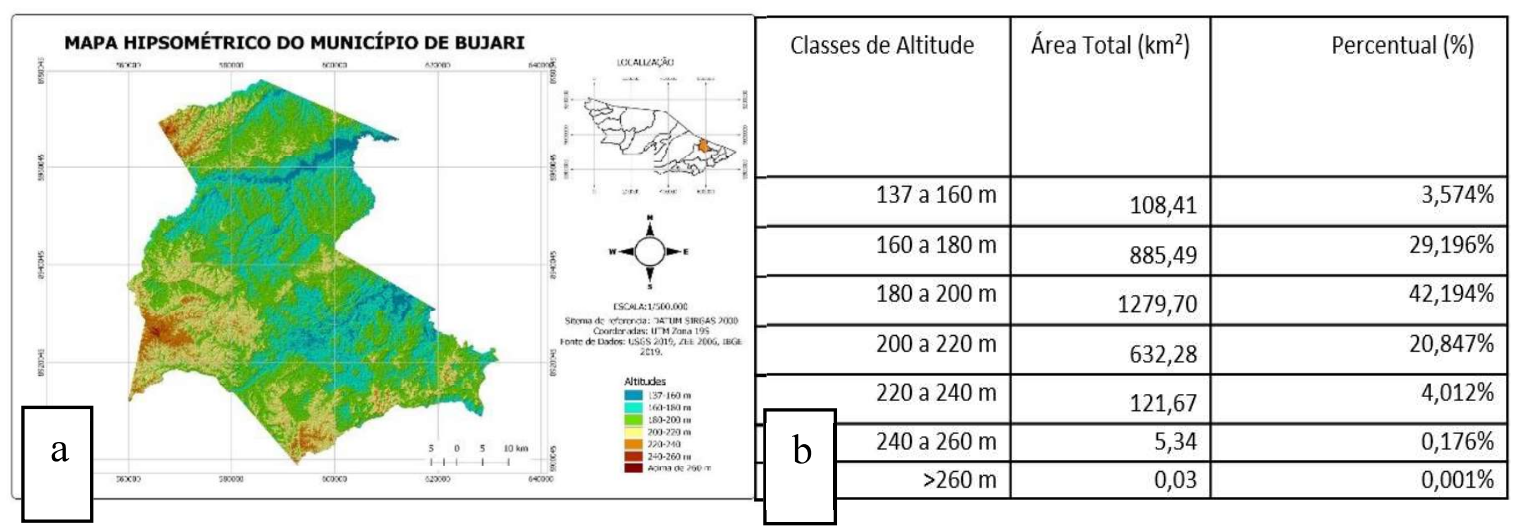

De acordo com a classificação geomorfológica para o Estado do Acre apresentada por Cavalcante (2006), o território do município de Bujari, apresenta, portanto, três feições geomorfológicas sendo a maior parte cerca de $2.784 \mathrm{Km}^{2}(91 \%)$ do município, formada pela Depressão Rio Branco, cerca de 159,368 Km² (5\%) pela Depressão Iaco Acre e 129,426 Km² (4\%) pela Depressão Planície Amazônica. Foi possível verificar algumas características como 
áreas de relevo levemente ondulado, mais comum na Depressão Rio Branco, e áreas de planícies inundáveis presente nas margens dos igarapés que banham o território municipal.

\subsection{Solos}

As características dos solos como já sabemos, é herdada do seu material de origem, que como já visto anteriormente os solos do Acre apresentam formação a partir de Rochas Sedimentares por meio de longos processos de intemperismo físico e químico transformando a rocha em solo. Nesse contexto o município de Bujari apresenta em seu território 5 tipologias de solos identificadas de acordo com dados geográficos do Zoneamento Ecológico Econômico do Acre - ZEE.

Grande parte do território cerca de $2.772,3 \mathrm{Km}^{2}$ está consolidado sobre solos do tipo Argissolos Vermelho Amarelo conforme (Figura 9). De acordo com Silva e Beiruth (2013), esse tipo de solo é caracterizado como profundos e velhos podendo ser distróficos ou eutróficos localizados em áreas de relevo suave ondulado podendo apresentar caráter alumínio ou alítico.

Ainda sobre a classificação dos Argissolos o município apresenta uma pequena variação dessa tipologia. Verificou-se uma pequena porção localizada a Noroeste do município de cerca de 63,509 $\mathrm{Km}^{2}$ de solos do tipo Argissolos Vermelhos.

Cerca de $129,43 \mathrm{~km}^{2}$ de solos do tipo Gleissolos. Para Silva e Beiruth (2013) Essa tipologia é característica de áreas próximas ao leito de rios e igarapés apresentam relevo plano (planície aluvial) apresentam coloração acinzentada e ricos em matéria orgânica e mal drenados.

Além das tipologias já apresentadas no território constatou-se ainda cerca de 92,895 $\mathrm{KM}^{2}$ de solos do tipo Luvissolos localizados mais ao Sul e uma pequena porção cerca de 14,427 $\mathrm{KM}^{2}$ de solo do tipo Plintossolo também localizada na região mais a Noroeste do município.

De acordo com o Manual Técnico de Pedologia - IBGE $2^{\mathrm{a}}$ Edição, os Luvissolos são solos de profundidade mediana, com cores desde vermelhas a acinzentadas argila de atividade alta, e alta saturação por bases, já os Plintossolos caracterizam-se principalmente pela presença de expressiva plintitização com ou sem petroplintita (concreções de ferro ou cangas). 


\subsection{Hidrografia}

No contexto Nacional de acordo com a Agência Nacional de Águas - ANA, o município de Bujari encontra-se localizado na Região Hidrográfica da Amazônia. Região Hidrográfica são bacias, grupo de bacias ou sub-bacias hidrográficas próximas, com características naturais, sociais e econômicas similares. (ANA, 2019).

No âmbito estadual de acordo com o Plano Estadual de Recursos Hídricos do Acre PLERH-AC 2012, o município está localizado na Bacia Hidrográfica Acre tendo como canal de drenagem principal o Rio Acre.

De acordo com os resultados das análises realizadas, foi possível a identificação de todas as bacias hidrográficas dentro do perímetro municipal. O território é dividido em 06 bacias hidrográficas. Os dois principais mananciais que banham o município são dois importantes afluentes do Rio Acre o Igarapé Riozinho e o Rio Antimary. Esses dois mananciais formam as duas principais bacias hidrográficas do município em termos de abrangência.

Abaixo apresentamos alguns dados extraídos do processamento digital dos principais mananciais e suas respectivas bacias.

Tabela 2: Morfometria das bacias Hidrográficas

\begin{tabular}{|c|c|c|c|c|c|c|c|c|c|c|c|}
\hline \multirow[b]{2}{*}{ Nome } & \multirow{2}{*}{$\begin{array}{r}\text { Extensão } \\
\text { linear } \\
(\mathrm{Km})\end{array}$} & \multirow{2}{*}{$\begin{array}{r}\text { Perímetro } \\
(\mathrm{Km})\end{array}$} & \multirow{2}{*}{$\begin{array}{r}\text { Drenagem } \\
\left(\mathrm{Km}^{2}\right)\end{array}$} & \multirow{2}{*}{$\begin{array}{l}\text { Padrão de } \\
\text { drenagem }\end{array}$} & \multicolumn{7}{|c|}{ Hierarquia fluvial } \\
\hline & & & & & $1^{\mathrm{a}}$ & $2^{\mathrm{a}}$ & $3^{a}$ & $4^{a}$ & $5^{a}$ & $6^{a}$ & $7^{a}$ \\
\hline $\begin{array}{l}\text { Ig. } \\
\text { Riozinho }\end{array}$ & 40 & 305 & 1.366 & Dendrítico & 1.255 & 632 & 326 & 165 & 43 & 28 & - \\
\hline $\begin{array}{l}\text { Rio } \\
\text { Antimary }\end{array}$ & 45 & 317 & 1.217 & Dendrítico & 1.127 & 552 & 320 & 141 & 17 & 71 & 34 \\
\hline $\begin{array}{l}\text { Ig. Rio } \\
\text { Branco }\end{array}$ & 24 & 124 & 390 & Dendrítico & 387 & 191 & 84 & 59 & 29 & - & - \\
\hline
\end{tabular}

Como visto na tabela acima as bacias mais desenvolvidas dentro do perímetro municipal são as do Igarapé Riozinho e a do Rio Antimary, ambas com suas áreas de drenagem ocupando cerca de $85 \%$ do território municipal.

A área de abrangência dessas bacias é significativamente grande como já mencionado acima com muitos pequenos canais de drenagem. A ação antrópica nessas áreas é de certa forma comum pois tudo ocorre dentro do contexto dessas bacias, por exemplo, a cidade, atividade pecuária, desmatamento, queimadas e agricultura familiar uma vez que o município desenvolve 
tais práticas. Quanto ao padrão de drenagem pode-se constatar com base em Christofoletti (1980) que todas as bacias de drenagem apresentam um padrão de drenagem Dendrítica.

O ordenamento dos canais de Figura 03: Bacias hidrográficas do município. drenagem foi realizado de acordo com a metodologia proposta por Strahler (1952), citado por Christofoletti (1980), em que há a ordenação do canais começando do número 1 (primeira ordem) para os canais sem tributários e que vão aumentando sua ordem a medida em que ocorra confluência com outros canais tributários formando assim a hierarquia fluvial. (CHISTOFOLETTI,

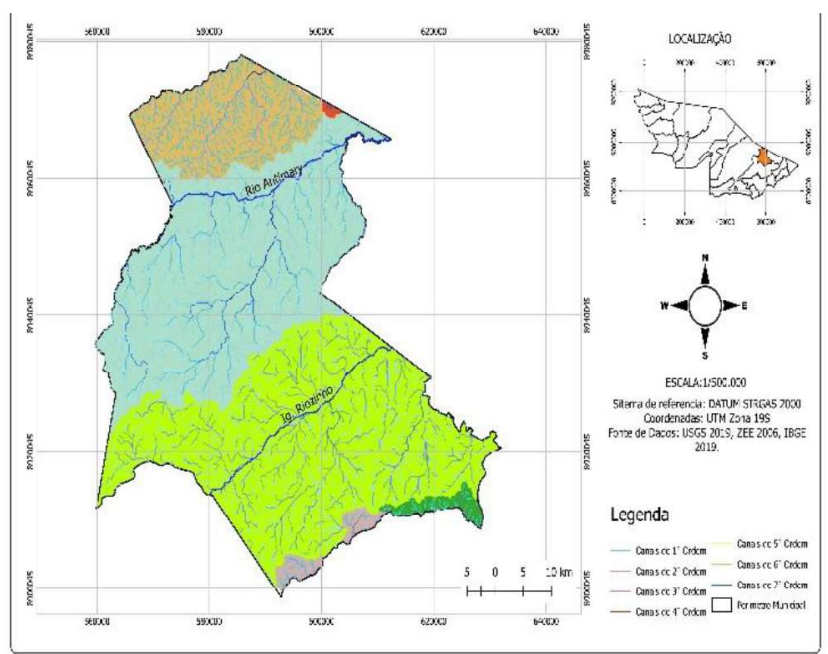

Fonte: Autor, 2019. 1980).

\subsection{Vegetação}

A retirada da cobertura florestal é intensificada nas propriedades particulares ao longo da rodovia, mas há também a presença de desmatamento em áreas de Assentamentos de Reforma Agrária. Na parte mais ao sul do município, já fora da rota da BR 364 e onde localizase a única Unidade de Conservação do município a Floresta Estadual do Antimary, observa-se menos a presença de supressão florestal o que pode ser explicado em função das regras de uso dessa Unidade de Conservação.

Apesar de suas áreas já desflorestadas o município ainda detém de muitas áreas de florestas como podemos visualizar na figura abaixo. Por meio do diagnóstico realizado de acordo com os dados do ZEE, constatou-se que na área de estudo existe uma variação na vegetação de pelo menos nove (09) tipologias diferentes sendo: FAB + FAP - Floresta Aberta + Floresta Aberta com Palmeira; FAB + FAP + FD - Floresta Aberta + Floresta Aberta com Palmeira + Floresta Densa; FAB + FD - Floresta Aberta + Floresta Densa; FABD - Floresta Aberta Densa; FAP - Floresta Aberta com Palmeira; FAP Aluvial - Floresta Aberta com Palmeira Aluvial; FAP + FAB - Floresta Aberta com Palmeira + Floresta Aberta; FAP + FD Floresta Aberta com Palmeira + Floresta Densa e FD + FAP - Floresta Densa + Floresta Aberta com Palmeira. Fig. 03. 
Dentre as principais tipologias destacamos as de maior relevância ocupacional no território como as Floresta Aberta + Floresta Aberta com Palmeira. Os remanescentes dessa tipologia cobrem ainda aproximadamente $66 \%$ do território municipal formadas na extensa área de argissolos vermelhos.

\subsection{Uso do Solo}

De acordo com a análise realizada foram identificados três diferentes tipos de uso e ocupação do solo predominantes no território municipal. As principais e mais expressivas formas estão distribuídos entre Propriedades Particulares que normalmente são Fazendas de criação de gado e os Projetos de Assentamentos de reforma Agrária com variações entre Projetos de Assentamento - PA, Projetos de Assentamento Agroextrativista - PAE e Projeto de Assentamento Dirigido - PAD.

Além dessas modalidades uma extensa área do município é ocupada pela Floresta Estadual do Antimary classificada como Unidade de Conservação - UC. Nesta modalidade de assentamento as famílias assentadas fazem uso do extrativismo vegetal principalmente a coleta de castanha-do-brasil Bertholletia excelsa além da prática da agricultura de subsistência com a comercialização do excedente produtivo.

No território ainda existe um Polo Agroflorestal, esta modalidade de uso consiste em uma área adquirida pelo Governo localizada bem próximo do núcleo urbano da cidade com o intuito do fomento à produção agroflorestal. No Polo Dom Moacir as famílias optaram pelo cultivo de hortaliças e criação de peixes e pequenos animais. Normalmente as famílias assentadas comercializam sua produção no município de Bujari e Rio Branco.

Nas demais modalidades de Assentamentos vivem e trabalham agricultores familiares que produzem para sua subsistência e comercializam o seu excedente produtivo como forma de garantia de uma renda extra para seu sustento.

Para cada uma dessas modalidades há uma forma de uso específico do solo. No entanto, observou-se de acordo com os dados do INPE/2019, um incremento no desmatamento anual presente em quase todas as modalidades de uso da área estudada. Apesar das extensas áreas já desflorestadas, foi possível verificar que grandes áreas ainda continuam a ser desmatadas.

A questão do desmatamento é evidente conforme apresentado na Fig. 04 acima, independente da forma de ocupação do solo. Cabe aos órgãos de gestão e fiscalização no caso das terras públicas, a cabível intervenção no sentido de apresentar propostas condizentes com 
a realidade e potencialidade dessas terras, oferecendo políticas de produção responsável e de incentivo a permanência da população campesina nessas localidades.

Figura 04: (a) Desmatamento Acumulado 2013-2018, (b) Índice de desmatamento por classe.
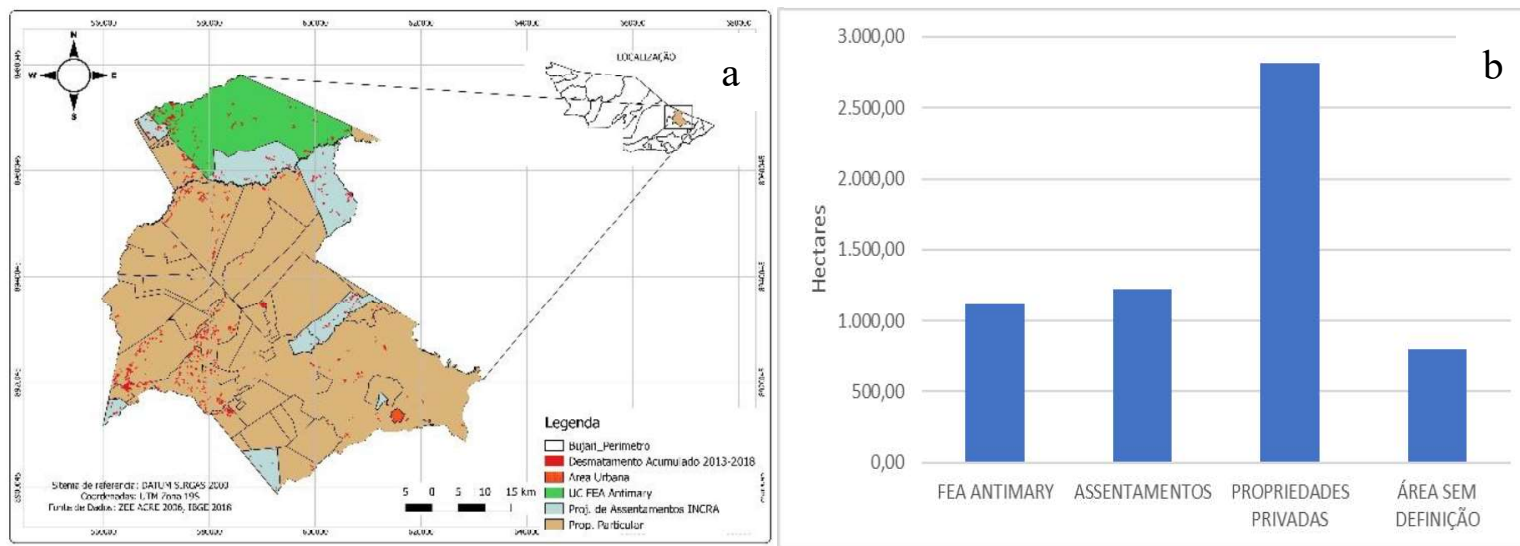

Fonte de dados desmatamento INPE 2019. Organização: Autor, 2019.

\section{CONSIDERAÇÕES FINAIS}

Com a realização deste estudo intitulado Caracterização Fisiográfica do Município de Bujari, foi possível obter uma base inicial de informações espaciais que poderá servir como subsídio na elaboração de um futuro zoneamento geoambiental ou mesmo de um futuro Plano Diretor municipal.

Partindo do marco zero onde não havia nada ou quase nada de informação espacial para o município, com a etapa de obtenção e posterior cruzamento e processamento dos dados coletados, foi possível extração de novas informações espaciais e como produto final dessa sistematização, a obtenção da espacialização por meio da representação gráfica dos principais elementos ambientais presentes na área de estudo.

Com a pesquisa foi possível obter uma ideia geral da espacialização dos principais elementos geoambientais presentes na extensão territorial do município bem como suas potencialidades e fragilidades também presentes. Constatou-se a grande malha hídrica do município, bem como a área de abrangência das bacias hidrográficas, mas também a constatação dos impactos da ação antrópica principalmente por meio da retirada da floresta sobre essas regiões de bacia ocasionando problemas ambientais no contexto das bacias hidrográficas.

Permitiu-nos visualizar as principais formas de uso do solo desenvolvidas no município bem como quantificá-las e de que forma estão especializadas permitindo entender onde estão 
localizadas as diferentes maneiras de uso bem como seus impactos ambientais. Nesse caso destacamos o da supressão florestal detectado objeto discutido em nossa pesquisa.

Por fim este trabalho permitiu-nos também evidenciar as potencialidades do uso da ferramenta SIG para análise espacial, pois, permite uma análise de grandes áreas em um curto espaço de tempo, por isso, recomendamos seu uso em trabalhos técnicos, sobretudo nas prefeituras em suas inúmeras demandas de planejamento territorial e os mais diversos mapeamentos.

\section{REFERÊNCIAS}

ANA. Agência Nacional de Águas. As 12 regiões hidrográficas brasileiras, região hidrográfica amazônica. Disponível em: http://www3.ana.gov.br/portal/ANA/as-12-regioeshidrograficas brasileiras/amazônica. Acesso em: 18 maio 2019.

BATISTELA. T. S. O zoneamento ambiental e o desafio da construção da Gestão Ambiental Urbana. 2007. 159 f. Dissertação (Mestrado em Arquitetura e Urbanismo) Universidade de Brasília - UnB, Faculdade de arquitetura e Urbanismo - FAU. 2007.

BRASIL. Constituição da República Federativa do Brasil: texto constitucional promulgado em 5 de outubro de 1988, com as alterações determinadas pelas Emendas Constitucionais de Revisão nos 1 a 6/94, pelas Emendas Constitucionais nos 1/92 a 91/2016 e pelo Decreto Legislativo no186/2008. - Brasília: Senado Federal, Coordenação de Edições Técnicas, 2016.

CABRAL, T, L. Zoneamento e mapeamento Geoambiental no município de Sorriso - MT. 2014. 131 p. Dissertação (Mestrado em Geografia). Universidade Federal de Santa Maria - Rio Grande do Sul. 2014.

CAVALCANTE, L. M. Aspectos geológicos do estado do Acre e implicações na evolução da paisagem Rio Branco, AC: Embrapa Acre, 2006. 25 p. il. color. (Embrapa Acre. Documentos, 104)

CHRISTOFOLETTI. A. Geomorfologia. São Paulo. Edgard Blucher, 2a Edição, 1980.

INSTITUTO BRASILEIRO DE GEOGRAFIA E ESTATÍSTICA - IBGE. Manual Técnico de Pedologia, $2^{\mathrm{a}}$ edição. Rio de Janeiro: Ministério do Planejamento, Orçamento e Gestão. Instituto Brasileiro de Geografia e Estatística - IBGE. Diretoria de Geociências. Coordenação de Recursos Naturais e Estudos Ambientais. Manuais Técnicos em Geociências, número 4, 2007, p. 316.

INSTITUTO BRASILEIRO DE GEOGRAFIA E ESTATÍSTICA - IBGE. Mapa geológico do Estado do Acre, Diretoria de Geociência, 2005. Disponível em: ftp://geoftp.ibge.gov.br/informacoes ambientais/geologia/levantamento_geologico/mapas/uni dades_da federacao/ac_geologia.pdf Acesso em: 13 jun. 2019.

INSTITUTO BRASILEIRO DE GEOGRAFIA E ESTATÍSTICA - IBGE. Cidades. Disponível em: https://cidades.ibge.gov.br/brasil/ac/bujari/historico. Acesso em: 13 jun. 2019. 
INSTITUTO NACIONAL DE PESQUISAS ESPACIAIS. Coordenação geral de observação da terra. Programa de Monitoramento da Amazônia e demais biomas. Desmatamento Amazônia Legal - Disponível em: http://terrabrasilis.dpi.inpe.br/downloads/. Acesso em: 14 jun. 2019.

LIMBERGER. L. Abordagem Sistêmica e Complexidade na Geografia. Geografia - v. 15, n. 2, jul./dez. 2006. Disponível em http://www.uel.br/revistas/geografia.

MARQUES NETO, R. A Abordagem Sistêmica e os Estudos Geomorfológicos: Algumas Interpretações e Possibilidades de Aplicação. Geografia - v. 17, n. 2, jul./dez. 2008 Universidade Estadual de Londrina, Departamento de Geociências.

NEVES, C. E das. Geossistema: A História De Uma Pesquisa - Trajetórias e Tendências no Estado de São Paulo. 2015. 191 f.: il. Dissertação (Mestrado em Geografia) Universidade Estadual de Londrina - UEL Paraná. 2015.

OLIVEIRA A, V, L, C de. Caracterização do Território para subsidiar o Zoneamento Geoambiental do município de Currais Novos - RN. In: Zoneamento Geoambiental como Subsídio ao Planejamento Territorial Municipal: estudo de caso para Currais Novos/RN 2012. 109 f. Dissertação (Desenvolvimento e Meio Ambiente) Universidade Federal do Rio Grande do Norte - UFRGN, Natal-RN 2012.

PLERH - AC. Plano Estadual de Recursos Hídricos. Rio Branco Acre. 2012.

SILVA, J.R.T. e BEIRUTH, L.J.V. Fundamentos de Pedologia. Solos do Acre (2013).

SOUZA. A. P. C. A. de. Ordenamento territorial: uma análise do macrozoneamento de Ipirá. 2010.

TORRES, M. C. Bujari. 1a Edição. Bujari Acre. 1996. 